\title{
Empirical evidence for fast temperature-dependent body size evolution in rotifers
}

\author{
Aleksandra Walczyńska 1 • Lluis Franch-Gras • Manuel Serra
}

Received: 20 January 2017/Revised: 10 April 2017/Accepted: 17 April 2017/Published online: 25 April 2017

(C) The Author(s) 2017. This article is an open access publication

\begin{abstract}
Organisms tend to decrease in size with increasing temperature by phenotypic plasticity (the temperature-size rule; ectotherms) and/or genetically (Bergmann's rule; all organisms). In this study, the evolutionary response of body size to temperature was examined in the cyclically parthenogenetic rotifer Brachionus plicatilis. Our aim was to investigate whether this species, already known to decrease in size with increasing temperature by phenotypic plasticity, presents a similar pattern at the genetic level. We exposed a multiclonal mixture of $B$. plicatilis to experimental evolution at low and high temperature and monitored body size weekly. Within a month, we observed a smaller size at higher temperature, as compared to body size at lower temperature. The pattern was consistent for the size of both mature females and eggs; rotifers kept at high temperature evolved to be on average 14\% (after 2 weeks) and 3\%
\end{abstract}

Guest editors: M. Devetter, D. Fontaneto, C. D. Jersabek, D. B. Mark Welch, L. May \& E. J. Walsh / Evolving rotifers, evolving science

A. Walczyńska ( $\square)$

Institute of Environmental Sciences, Jagiellonian University, Gronostajowa 7, 30-387 Kraków, Poland

e-mail: aleksandra.walczynska@uj.edu.pl

L. Franch-Gras · M. Serra

Institute Cavanilles for Biodiversity and Evolutionary

Biology, University of Valencia, A.O. 2085,

E46071 Valencia, Spain (after 3 weeks) smaller than the ones kept at low temperature (10 and 5\% in the case of eggs, respectively). We therefore found that $B$. plicatilis is genetically programmed to adjust its body size-toenvironmental temperature.

Keywords Bergmann's rule $\cdot$ Body size . Brachionus plicatilis · Experimental evolution . Temperature-size rule

\section{Introduction}

The relationship between body size and temperature is an issue widely studied and discussed. The main reason for this is because body size is a central lifehistory trait, linked directly to organismal fitness (Kozłowski, 1992; Roff, 1992; Stearns, 1992), while temperature is one of the most important environmental factors influencing evolution and diversification (Woese, 1987; Pace, 1991; Nisbet \& Fowler, 1996; Takemoto \& Akutsu, 2008). Indeed, organisms change their size in response to short-term environmental changes through phenotypic plasticity and during the more extended process of evolutionary adaptation to geographically distinct and thermally differing locations. The phenomenon of achieving smaller size at maturity at higher temperature through phenotypic plasticity in ectotherms is known as the temperature-size rule (Atkinson, 1994), while the same pattern at a larger geographic scale through 
genetic adaptation was termed Bergmann's rule (Bergmann, 1847), now extended from its original focus on vertebrates to all organisms (Blanckenhorn \& Demont, 2004). Several other rules describing a similar pattern from different points of view were proposed (Blackburn et al., 1999; McNab, 2010; Alho et al., 2011; Pintor et al., 2015), but the most important is that despite these different points of view, the observation of growing larger at colder temperatures is so common in nature.

In this study, we grew Brachionus plicatilis Müller, 1786, a cyclically parthenogenetic rotifer, in two selective environments- - low and high temperaturein order to test for temperature-dependent evolution in size. B. plicatilis was previously regarded as a cosmopolitan species of a global geographic range. Molecular techniques have shown that the former taxon B. plicatilis is actually a complex of fifteen cryptic species (Mills et al., 2017). Four species from this complex co-exist in the shallow ponds of the Mediterranean coast of Spain (Gomez et al., 1995; Ortells et al., 2003; Montero-Pau et al., 2011). Recently, three of them, B. plicatilis sensu stricto Müller, 1786, B. ibericus Ciros-Pérez, Gómez \& Serra, 2001 and B. rotundiformis Tschugunoff, 1921 were examined for size-dependent temperature preference. The results show that (i) species size correlates with the thermal dependence of diapause egg hatching (Walczyńska \& Serra, 2014b), (ii) optimal temperature varies among species with a tendency for smaller species to prefer higher temperatures (Walczyńska \& Serra, 2014a), and (iii) the temperature-size rule response differs between species; $B$. plicatilis sensu stricto was the only one of the three species following this rule (Walczyńska \& Serra, 2014a).

Our aim was to examine the possible evolution of body size of $B$. plicatilis sensu stricto in response to low or high temperature. As it happens in the wild, in our experiments, several environmental factors (e.g., oxygen concentration, food quality, etc.) might or certainly do correlate with the experimental temperature. In this way, we addressed the global effect of temperature due to direct and indirect pathways. Herein, we test if size response to temperature is heritable in B. plicatilis via experimental evolution, a powerful tool for testing evolutionary hypotheses in real time (Garland \& Rose, 2009; Sanjuan and Domingo-Calap, 2011). Monogonont rotifers act as a very useful and successful model for micro- evolutionary studies (Fussmann, 2011; Declerck \& Papakostas, 2017). As reviewed by Declerck \& Papakostas, (2017, this issue), experimental evolution was previously used in the case of rotifers to test hypotheses on the evolution of sex (Becks \& Agrawal, 2010, 2012, 2013; Fussmann et al., 2003), the combination of different life-history traits (Stelzer, 2011; Smith \& Snell, 2014), and the adaptation to food composition (Declerck et al., 2015). The most recent studies using experimental evolution in rotifers focus on sexual reproduction (Haafke et al., 2016) and bethedging strategy (Tarazona et al., 2017). In the present study, we focus on body size, a single, crucial lifehistory trait, evolving in response to temperature. Our hypothesis is that exposure to low or high temperatures selects $B$. plicatilis rotifers toward larger or smaller size at maturity, respectively. We observed an evolutionary size-to-temperature response within a month.

\section{Materials and methods}

\section{Brachionus plicatilis}

Brachionus plicatilis is a monogonont rotifer occurring in brackish ponds and lagoons. Their populations are seasonally active in the water column. The growing season starts when diapausing, resistant eggs located in the sediment hatch. Parthenogenetic reproduction continues during a variable number of generations, so that a clone is produced from each dormant egg hatched. B. plicatilis populations harbor high variability in fitness components (Campillo et al., 2011). Due to clonal selection, genetic diversity is expected to be higher in the dormant egg bank than in the active population. Even so, considerable genetic diversity has been reported in active rotifers within one pond (Gómez \& Carvalho, 2000). B. plicatilis lifehistory rates depend on temperature, salinity, and food supply (Miracle \& Serra, 1989; Ciros-Pérez et al., 2001). For instance, in laboratory conditions, at $15^{\circ} \mathrm{C}$, the intrinsic rate of population growth $(r)$ amounts to 0.36 day $^{-1}$ and lifespan lasts around 15 days (one literature source), while at $25^{\circ} \mathrm{C} r$ varies between 0.32 and 0.96 day $^{-1}$, and the lifespan ranges between 6 and 13.5 days (seven different scientific reports; Miracle $\&$ Serra, 1989). In the previous study conducted using the same food source as in the presented study, 
intrinsic population growth rate was $0.71 \mathrm{day}^{-1}$ at $17.5^{\circ} \mathrm{C}$ (lowest temperature examined) and 1.19 day $^{-1}$ at $25^{\circ} \mathrm{C}$ (data from Walczyńska \& Serra, 2014a). Most of B. plicatilis body growth occurs before maturity.

Clones of B. plicatilis were obtained by asexual proliferation of individual females hatched from single diapausing eggs isolated from sediments of three shallow, brackish ponds: Atalaya de los Ojicos $\left(38^{\circ} 46^{\prime} 20.97^{\prime \prime} \mathrm{N}, \quad 1^{\circ} 25^{\prime} 49.12^{\prime \prime} \mathrm{W}\right)$, Hoya Rasa $\left(38^{\circ} 47^{\prime} 6.06^{\prime \prime} \mathrm{N}, 1^{\circ} 25^{\prime} 37.56^{\prime \prime} \mathrm{W}\right)$, and La Campana $\left(38^{\circ} 51^{\prime} 29.06^{\prime \prime} \mathrm{N}, 1^{\circ} 29^{\prime} 36.97^{\prime \prime} \mathrm{W}\right)$ (Franch-Gras et al., in prep). The sediment of each pond was sampled from the uppermost $10 \mathrm{~cm}$ with a Van Veen grab. The clones were identified as being $B$. plicatilis using molecular markers (Campillo et al., 2005). For this experiment, stock cultures of five clones per population were individually maintained at $20^{\circ} \mathrm{C}$ and $12 \mathrm{ppt}$ salinity. The culture medium initially contained $3 \times 10^{5}$ cells $/ \mathrm{ml}$ of the microalgae Tetraselmis suecica as food for rotifers. Previously to be supplied, microalgae were maintained in exponential growth phase and constant illumination with f/2-enriched saline water (Guillard \& Ryther, 1962) prepared with commercial sea salt (Instant Ocean ${ }^{\circledR}$; Aquarium Systems) at $20^{\circ} \mathrm{C}$ and $12 \mathrm{ppt}$ salinity. Before the experiment, the clones were maintained under experimental conditions at $20^{\circ} \mathrm{C}$ for 18 months, and fed weekly.

\section{Experimental setup}

Our experiment consisted of two standard phases (e.g., Sanjuan \& Domingo-Calap, 2011); experimental evolution-described in this subsection-and performance testing (i.e., measuring the selection response; Fig. 1). In our case, the tested trait was body size. For the experiments, we used 14-15 clones (4-5 clones $\times 3$ ponds). With these clones, we founded six laboratory populations, each composed of a multiclonal mixture of 10 females per clone, and the clone composition was identical for each experimental population (15 clones) except for a clone of Hoya Rasa (a poorly growing clone), which was only added to two laboratory populations, one per each treatment (14 clones). Each population was grown in flasks with $250 \mathrm{ml}$ of artificial seawater (Instant Ocean ${ }^{\circledR}$, Aquarium Systems) at $12 \mathrm{ppt}$ salinity as medium, and Tetraselmis suecica algae as food (initial concentration: $8 \times 10^{5}$ cells $\left./ \mathrm{ml}\right)$, under continuous light $\left(75 \mu \mathrm{mol}\right.$ quanta $\left.\mathrm{m}^{-2} \mathrm{~s}^{-1}\right)$. Experimental populations were exposed to thermal treatments of 15 and $25^{\circ} \mathrm{C}$ (three populations-replicates-per treatment) using climatic chambers. Once a week, $50 \mathrm{ml}$ of each culture was replaced with fresh medium and rotifers were fed with $8 \times 10^{5}$ cells $/ \mathrm{ml}$ of the microalgae Tetraselmis suecica. The experimental cultures were maintained in this way for 1 month.

\section{Measuring the selection response}

In order to isolate the effect of temperature on size evolution, body size has to be measured after removing maternal effects and the effect of temperature via developmental plasticity (Fig. 1). In this way, the environmental effect on body size is controlled for, and the remaining significant differences, if observed, are genetically caused. This control was made using a common garden condition at $20^{\circ} \mathrm{C}$. For this purpose, every week during the experimental month-experimental onset included-50 ovigerous females (i.e., females with eggs attached) per experimental population were randomly chosen and transferred in groups of five to wells in 24-well plates, containing $1 \mathrm{ml}$ of the culture medium (as above), and kept at $20^{\circ} \mathrm{C}$. Daughters were transferred to wells with fresh medium; this process was repeated for three generations (Stelzer \& Snell, 2006). Then, ovigerous, asexual females of the third generation were fixed with Lugol solution and measured under an inverted microscope (Olympus CK2). The metric for size was an approximation of volume, assumed to be an ellipsoid shape for adults (Ruttner-Kolisko, 1977). As height was not measured, we assumed an ellipsoid of revolution:

$V=(4 / 3) \times 3.14 \times$ length $\times$ width $\times$ width.

Eggs from the third-generation females were also measured according to the same metric.

Data analysis

Adult size and egg size (traits) were analyzed separately. In order to reduce variation associated with different ages of mature females, measurements were performed on females bearing up to two eggs. This was the largest number of attached eggs common for all the samples analyzed (within the combinations of treatment $\times$ population $\times$ time). Two mixed model 
Fig. 1 Scheme of the setup testing for experimental evolution for size in Brachionus plicatilis rotifers exposed to low or high temperatures. Three experimental populations per thermal treatment were evolving for 1 month and sampled weekly. Sampled females (F0 generation) were transferred individually and maintained in common conditions, the procedure being repeated with their direct and indirect descendants in order to measure F3 individuals

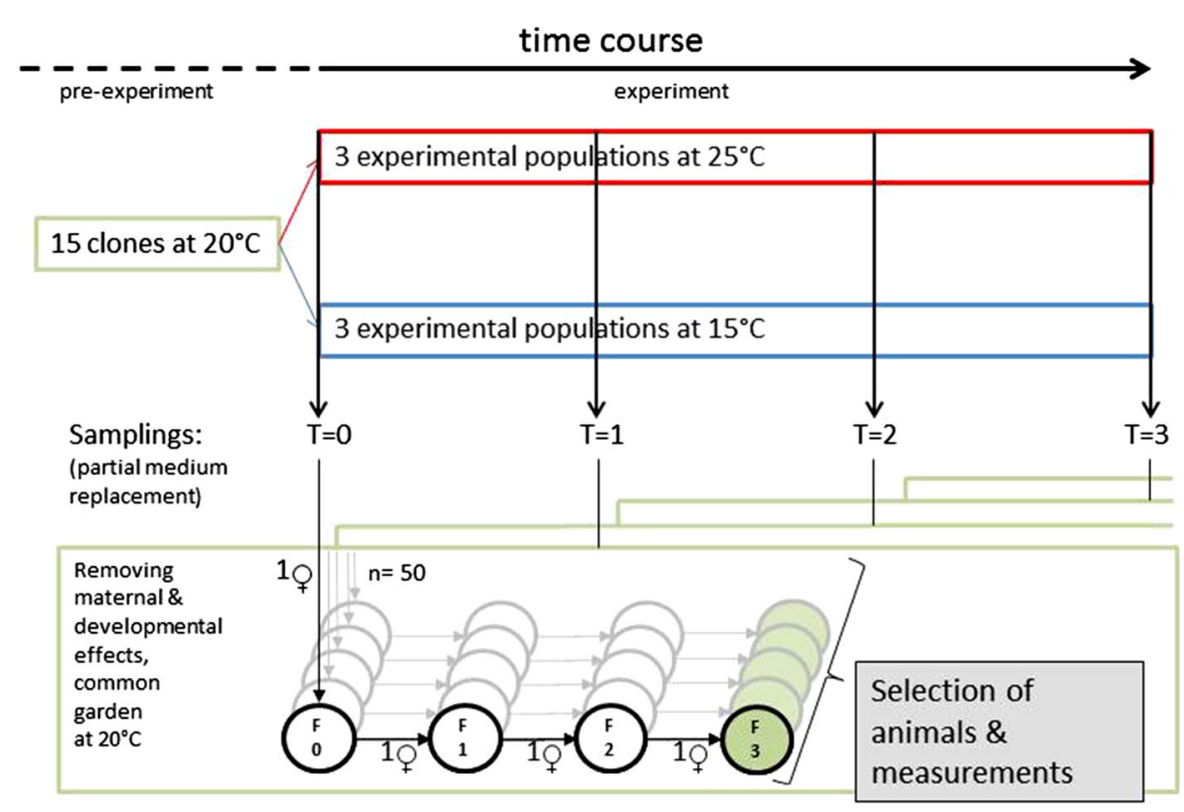

ANOVAs were applied to each trait. The first one tested for differences in size at the beginning of the experiment (pre-experimental size; $T=0$ ), with treatment (temperature, fixed) and population (random, nested within treatment) as independent factors. Accordingly, the grouping of animals in wells, where animals were grown to control for plasticity and maternal effects, was ignored in our data analysis design, and all the measurements for an experimental population within a treatment were merged in order to estimate the model error. The first of these Mixed Model ANOVAs worked as a control to test if significant initial differences between temperature treatments occurred randomly. That is, the null hypothesis (no treatment effect) was expected in this ANOVA. The second one tested for differences in size in response to selection, and focused on the measurements taken in the last 2 weeks $(T=2$ and $T=3)$. In this second mixed model ANOVA, the factors were treatment (temperature; fixed), time (i.e., week; fixed), and population (random, nested within treatment). Again, all the measurements for the combination of a time and an experimental population within a treatment were merged, in order to estimate the model error. We selected $T=2$ and $T=3$ as a compromise between two criteria: (a) enough time for evolution to occur should be considered, i.e., we did not include $T=1$, and (b) increased statistical power. Notice that by not restricting to $T=3$, model error has more degrees of freedom, and the mean square for the treatment is computed using more values. These ANOVAs were carried out using PROC GLM in SAS (SAS Institute Inc., v.9.4). It is worth noting that the hypothesis on a treatment effect is unidirectional, as we expected rotifers from low temperature to be larger than those from high temperature. Additionally, we tested whether a correlation in size occurred among experimental populations within treatment. A positive correlation might be indicative of dependence in the error term used by ANOVA to test for treatment effect.

\section{Results}

Divergence of average size in response to temperature was noticeable from the second week of the experiment, in the cases of adults and eggs alike, with lower average sizes found at higher temperatures (Table 1; Fig. 2). After controlling for developmental effects (phenotypic plasticity), adult rotifers at high temperature were on average 14\% (after two weeks) and 3\% (after three weeks) smaller than those maintained at high temperature, the corresponding values being 10 and $5 \%$ in the case of eggs. Notice that a monotonous trend with time was not observed for each temperature treatment, but that fluctuations were found. However, time correlation coefficients of the residuals (i.e., departures for the mean of the population $\times$ time 
Table 1 The body size of adult females and eggs (estimated

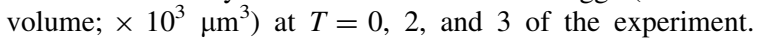
Mean \pm SD between populations

\begin{tabular}{lll}
\hline & Low temperature & High temperature \\
\hline Adult females & & \\
$T=0$ & $35,800 \pm 2,100$ & $36,400 \pm 1,600$ \\
$T=2$ & $45,000 \pm 3,800$ & $38,900 \pm 1,800$ \\
$T=3$ & $35,000 \pm 330$ & $33,900 \pm 1,700$ \\
Eggs & & \\
$T=0$ & $4370 \pm 470$ & $4030 \pm 440$ \\
$T=2$ & $4750 \pm 220$ & $4270 \pm 160$ \\
$T=3$ & $3880 \pm 140$ & $3700 \pm 80$ \\
\hline
\end{tabular}

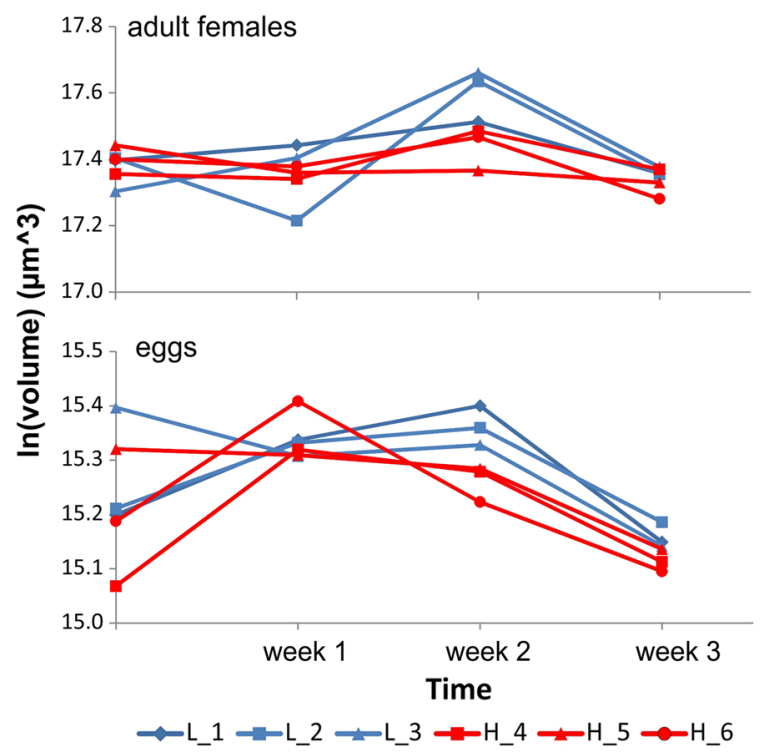

Fig. 2 Time-course relationship between Brachionus plicatilis body size, measured after controlling for maternal and developmental effects, and temperature. Upper panel mean adult size of females bearing one or two eggs; lower panel mean egg size. Three experimental populations per treatment are shown. Blue lines low temperature $(L)$; red lines high temperature $(H)$

combination) were not significant for adults or eggs, suggesting that populations tend to fluctuate independently around the non-monotonous variation associated to the environmental temperature. Preexperimental size did not differ significantly among adult females or eggs, although in the latter significant differences between experimental populations were detected (Table 2). Both adult females and eggs,
Table 2 ANOVAs on rotifer size (adult females or egg size) at the onset (pre-experimental size) and at the end of the experiment (post-experimental size; measured and analyzed for the last two sampling times)

\begin{tabular}{|c|c|c|c|}
\hline factors & df & $\mathrm{F}$ & $P$ \\
\hline \multicolumn{4}{|l|}{ Pre-experimental size } \\
\hline \multicolumn{4}{|l|}{ Adult females } \\
\hline Treatment & 1,41 & 0.18 & 0.6743 \\
\hline $\begin{array}{l}\text { Population } \\
\text { (Treatment) }\end{array}$ & 4,41 & 0.33 & 0.8557 \\
\hline \multicolumn{4}{|l|}{ Eggs } \\
\hline Treatment & 1,80 & 2.66 & 0.1069 \\
\hline $\begin{array}{l}\text { Population } \\
\text { (Treatment) }\end{array}$ & 4,80 & 4.87 & 0.0015 \\
\hline \multicolumn{4}{|l|}{ Post-experimental size } \\
\hline \multicolumn{4}{|l|}{ Adult females } \\
\hline Time & $1,4.51$ & 29.78 & 0.0038 \\
\hline Treatment $^{\mathrm{a}}$ & $1,4.41$ & 7.87 & 0.0217 \\
\hline $\begin{array}{l}\text { Population } \\
\text { (Treatment) }\end{array}$ & $4,4.00$ & 1.23 & 0.4229 \\
\hline Time $\times$ Treatment & $1,4.51$ & 3.90 & 0.1115 \\
\hline Time $\times$ Population & 4,177 & 0.98 & 0.4193 \\
\hline \multicolumn{4}{|l|}{ Eggs } \\
\hline Time & $1,4.72$ & 199.77 & $<0.0001$ \\
\hline Treatment $^{\mathrm{a}}$ & $1,4.24$ & 12.38 & 0.0111 \\
\hline $\begin{array}{l}\text { Population } \\
\text { (Treatment) }\end{array}$ & $4,4.00$ & 2.89 & 0.1641 \\
\hline Time $\times$ Treatment & $1,4.72$ & 5.14 & 0.0758 \\
\hline Time $\times$ Population & 4,185 & 0.36 & 0.8400 \\
\hline
\end{tabular}

Significant results are bolded

a $P$ value is for the unidirectional alternative hypothesis

measured in the last two time points of the experiment, were significantly larger at low temperature than at high temperature (Table 2; Fig. 2), with no difference between experimental populations or interaction of time with other factors (Table 2).

\section{Discussion}

We observed evolutionary changes in B. plicatilis size in response to temperature within a month. As expected, rotifers exposed to higher temperature evolved to smaller size at maturity than rotifers from lower temperature. Egg size evolved in the same direction as adult size. These results show that $B$. plicatilis rotifers, originally derived from the same 
mixture of natural populations, exhibit smaller size at higher temperature not only as a result of phenotypic (developmental) plasticity, which was previously reported by Walczyńska \& Serra (2014a), but also by a genetically determined shift in phenotype (this study). An alternative interpretation of our results is that rotifers decreased in size regardless of temperature, responding so to an experimental system involving population fluctuations due to dilutions. Such a response is predicted if our system would favor the $r$ strategists. Then the observed divergence between temperatures would be due to faster evolution at higher temperature (i.e., shorter generation time), but the unobserved evolutionary equilibrium would imply the same size regardless the temperature. Even if this explanation cannot be ruled out, it seems unlikely to us because rotifer populations-due to their fast growth-were exposed to a wide range of density conditions-including both density-independent and density-dependent - during the periods between dilutions. Additionally, Fig. 2 does not suggest divergence in the rates of evolution.

Even having observed an evolutionary response to environmental temperature, the environmental variable acting as a selective pressure might be a different one that would have been correlated in our cultures to temperature, namely food quality and quantity (e.g., as a result of competition) and possible deprivation of oxygen. Interestingly, solubility, and so concentration, of oxygen in water decreases with increasing temperature (Garcia \& Gordon, 1992; Denny, 1993; Wetzel, 2001). This fact has brought to propose that the advantage of smaller size at higher temperature is hypothesized to stem from the idea that with increasing temperature, the oxygen demands of organisms grow faster than oxygen availability (Verberk et al., 2011), and therefore small organisms deliver more oxygen to their tissues than large organisms (Woods, 1999). The driving role of oxygen in temperature-size rule was hypothesized by Atkinson et al. (2006). Since then, it was confirmed in several other studies (Czarnoleski et al., 2015; Hoefnagel \& Verberk, 2015; Horne et al., 2015; Walczyńska et al., 2015) and rejected in one meta-analysis (Klok \& Harrison, 2013). In the context of adaptive phenotypic plasticity, the temperature-size rule can be considered as being "responsive" (sensu Whitman \& Agrawal, 2009) with regard to temperature, but "anticipatory" with regard to oxygen, possibly because mechanisms of response to temperature are better developed than those of response to oxygen, as was previously suggested by Walczyńska et al. (2015).

Our results contribute to the important issue of matching the phenotypic and genetic levels of response to selection for evolutionary inference (Swallow \& Garland, 2005; Blanckenhorn, 2015; Merilae \& Hendry, 2014). The underlying explanatory factor in evolutionary inference is the adaptive significance of the observed change (Merilae \& Hendry, 2014; Teplitsky \& Millien, 2014). Indirect support for adaptation stems from a previous study showing that the body size of another rotifer species, Lecane inermis, was adaptive to combined temperature/oxygen conditions in accordance with the predictions of temperature-size rule (Walczyńska et al., 2015). Consistent with the invoked study, the temperature-size rule may be regarded as an adaptation to temperature-dependent oxygen conditions.

In the present study, we started from a mixture of clones that did not correspond to a single natural population. The rationale behind this arrangement was to increase the initial genetic variance, because we aimed at investigating the evolution of size in exposure to low or high temperatures, rather than in a specific population. However, because rotifers have high dispersal rates (Fontaneto \& De Smet, 2015), our experimental conditions might correspond to a natural scenario; for instance, when immigrants from several source populations colonize a new habitat.

In our experiments, average size did not change monotonically with time. Sampling effects might be involved in this. However, a non-monotonous response is also expected because of the rotifer lifecycle, due to the fact that a number of parthenogenetic generations have to be occurred in our cultures and that some sexual reproduction cannot be discarded. During the expectable clonal selection phase, all the expressed genetic variance-either additive or not-fuels evolution, making selection very effective. However, a fluctuating response can be caused by sexual reproduction, as sexual offspring would to some extent return towards the average phenotype preceding clonal selection. This phenomenon has been previously observed in other cyclical parthenogens (cladocerans) and has been termed slippage (Lynch \& Deng, 1994). Nevertheless, environmental factors difficult to control (e.g., food quality) might have also caused the observed fluctuations. Since we observed a 
clearer pattern for egg size than for adult size (Table 2; Fig. 2), we therefore argue that adult size is more sensitive to noise.

When environmental (phenotypic plasticity) and genetic (evolution) effects on trait variation act in the same direction, this occurrence of positive covariance is known as cogradient variation, while negative covariance between environmental and genetic variances is termed countergradient variation (Levins, 1968; Conover \& Schultz, 1995). The former pattern may increase phenotypic variation across environmental gradients, while the latter reduces it. Conover et al. (2009) provided a meta-analysis of existing data on cogradient and countergradient variation across ecological gradients in morphological, physiological, and reproductive traits in different organisms. They noted the countergradient pattern in the vast majority of cases, mostly in ectotherms and in physiological traits. This might be due to the need of keeping a stable phenotype regardless of environmental conditions, for instance, if phenotype is associated with biotic niche axes. Over $80 \%$ of case studies involving cogradient variation concerned morphological traits. Regarding body size, Conover et al. (2009) noted seven examples of countergradient variation and two examples of the cogradient pattern, both directional patterns in Drosophila. Additional information is provided by Taylor et al. (2015) in a study designed to examine the covariance pattern between temperature-size rule and Bergmann's rule in another Drosophila species. The authors observed countergradient variation in body size. Walczyńska \& Serra (2014a) and this study provide an example of cogradient variation. $B$. plicatilis body size changes in response to temperature in the same direction due to both phenotypic plasticity and genetic factors. These animals dwell in unpredictable habitats, which may promote a plastic response, but they harbor genetic variation for size, which can fuel selection and consequently adaptive evolution. The advantage of this study over previously mentioned investigations is that we used an experimental evolution method which is more powerful than comparative studies regarding the genetic basis of characters with complex evolutionary trajectories (Matos et al., 2004).

Apart from the methodology used, the apparent divergence in published results may stem from the frequent mismatch between generation time in relation to season length in the investigated organisms (Chown
\& Gaston, 1999; Blanckenhorn \& Demont, 2004; Horne et al., 2015). In such cases, the converse Bergmann's rule (sensu Blanckenhorn \& Demont, 2004) may be observed in relation to altitude or latitude, because the temperature effect is strictly intertwined with season length. This argument does not apply to our results because our model organism is a short-lived species not exposed to seasonality during the experiment (we estimate the population doubling time to $c$. 1 day at $15^{\circ} \mathrm{C}$ and 0.6 day at $25^{\circ} \mathrm{C}$ ). As Kozłowski (2006) noted: "The size of an organism is not given to the organism. It is developed by the organism, and development requires time, during which death is likely." From this perspective, body size is partly a morphological, physiological, and reproductive trait, and the pattern of change across a gradient should be interpreted in the context of other traits, such as development time, growth rate, and extrinsic mortality. Only this combination would provide reliable information on whether the results on body size we obtained reveal adaptive evolution or rather a constraint, for example, in the face of high extrinsic mortality or short developmental season. The advantage of our approach is the lack of extrinsic mortality and significant environmental change in the experimental setup. We may thus claim that our observation of smaller size at higher temperature is not due to a constraint.

The considerations presented above may underlie why temperature-size rule seems to be more general than Bergmann clines, as noted by Hessen et al. (2013). Our results, supported by other studies, indicate that the general phenomenon of body size decrease with increasing temperature may be common for different levels of response, i.e., genetic and phenotypically plastic. As a result, we advocate a focus on the proximate and ultimate mechanisms behind this phenomenon.

Acknowledgements We are grateful to Eva Tarazona and Ana Hidalgo for substantial assistance and advice throughout this study, Terézia Horváthová and Edyta Sadowska for helpful comments on previous versions of the text, and Maciej Pabijan for text editing. The study was funded from the project POKL.04.01.01-00-053/09, carried out in the Institute of Environmental Sciences (Jagiellonian University, Krakow, Poland), co-financed by the European Union under the European Social Fund, and by the Spanish Ministry of Economy and Competitiveness (CGL2009-07364). L. F-G was supported by a fellowship from the University of Valencia (PREDOC13-110502). 


\section{Compliance with ethical standards}

Conflict of interest The authors declare no conflict of interest.

Open Access This article is distributed under the terms of the Creative Commons Attribution 4.0 International License (http:// creativecommons.org/licenses/by/4.0/), which permits unrestricted use, distribution, and reproduction in any medium, provided you give appropriate credit to the original author(s) and the source, provide a link to the Creative Commons license, and indicate if changes were made.

\section{References}

Alho, J. S., G. Herczeg, A. T. Laugen, K. Rasanen, A. Laurila \& J. Merila, 2011. Allen's rule revisited: quantitative genetics of extremity length in the common frog along a latitudinal gradient. Journal of Evolutionary Biology 24(1): 59-70.

Atkinson, D., 1994. Temperature and organism size - a biological law for ectotherms. Advances in Ecological Research 25: 1-58.

Atkinson, D., S. A. Morley \& R. N. Hughes, 2006. From cells to colonies: at what levels of body organization does the 'temperature-size rule' apply? Evolution \& Development 8(2): 202-214.

Becks, L. \& A. F. Agrawal, 2010. Higher rates of sex evolve in spatially heterogeneous environments. Nature. doi:10. 1038/nature09449.

Becks, L. \& A. F. Agrawal, 2012. The evolution of sex is favoured during adaptation to new environments. PLoS Biology. doi:10.1371/journal.pbio.1001317.

Becks, L. \& A. F. Agrawal, 2013. Higher rates of sex evolve under K-selection. Journal of Evolutionary Biology 26(4): 900-905.

Bergmann, C., 1847. Uber die verhaltnisse der warmeokonomie der thiere zuihrer grosse. Gottinger Studien 1: 595-708.

Blackburn, T. M., K. Gaston \& N. Loder, 1999. Geographic gradients in body size: a clarification of Bergmann's rule. Diversity and Distributions 5: 165-174.

Blanckenhorn, W. U., 2015. Investigating yellow dung fly body size evolution in the field: Response to climate change? Evolution 69(8): 2227-2234.

Blanckenhorn, W. U. \& M. Demont, 2004. Bergmann and converse Bergmann latitudinal clines in Arthropods: two ends of a continuum? Integrative and Comparative Biology 44: 413-424.

Campillo, S., E. M. Garcia-Roger, D. Martinez-Torres \& M. Serra, 2005. Morphological stasis of two species belonging to the L-morphotype in the Brachionus plicatilis species complex. Hydrobiologia 546: 181-187. doi:10.1007/ s10750-005-4120-7

Campillo, S., E. M. Garcia-Roger, M. Jose Carmona \& M. Serra, 2011. Local adaptation in rotifer populations. Evolutionary Ecology 25(4): 933-947. doi:10.1007/s10682-010-9447-5

Chown, S. L. \& K. Gaston, 1999. Exploring links between physiology and ecology at macro-scales: the role of respiratory metabolism in insects. Biological Reviews 74: 87-120.
Ciros-Pérez, J., M. J. Carmona \& M. Serra, 2001. Resource competition between sympatric sibling rotifer species. Limnology and Oceanography 46(6): 1511-1523.

Conover, D. O. \& E. T. Schultz, 1995. Phenotypic similarity and the evolutionary significance of countergradient variation. Trends in Ecology \& Evolution 10(6): 248-252. doi:10. 1016/s0169-5347(00)89081-3

Conover, D. O., T. A. Duffy \& L. A. Hice, 2009. The covariance between genetic and environmental influences across ecological gradients reassessing the evolutionary significance of countergradient and cogradient variation. In Schlichting, C. D. \& T. A. Mousseau (eds) Year in Evolutionary Biology 2009. Annals of the New York Academy of Sciences, vol 1168: 100-129

Czarnoleski, M., J. Ejsmont-Karabin, M. J. Angilletta Jr. \& J. Kozlowski, 2015. Colder rotifers grow larger but only in oxygenated waters. Ecosphere. doi:10.1890/es15-00024.1.

Declerck, S. A. J., A. R. Malo, S. Diehl, D. Waasdorp, K. D. Lemmen, K. Proios \& S. Papakostas, 2015. Rapid adaptation of herbivore consumers to nutrient limitation: eco-evolutionary feedbacks to population demography and resource control. Ecology Letters 18(6): 553-562.

Declerck, S. A. J. \& S. Papakostas, 2017. Monogonont rotifers as model systems for the study of micro-evolutionary adaptation and its eco-evolutionary implications. Hydrobiologia. doi:10.1007/s10750-016-2782-y.

Denny, M. W., 1993. Air and Water. The Biology and Physics of Life's Media. Princeton University Press, Princeton and Chichester

Fontaneto, D. \& W. H. De Smet, 2015. Rotifera. In SchmidtRhaesa, A. (ed.), Gastrotricha, Cycloneuralia and Gnathifera, vol 3: Gastrotricha and Gnathifera. Handbook of Zoology. The Royal Swedish Academy of Sciences, Sweden: 217-300.

Fussmann, G. F., 2011. Rotifers: excellent subjects for the study of macro- and microevolutionary change. Hydrobiologia 662(1): 11-18.

Fussmann, G. F., S. P. Ellner \& N. G. Hairston, 2003. Evolution as a critical component of plankton dynamics. Proceedings of the Royal Society B-Biological Sciences 270(1519): 1015-1022.

Garcia, H. E. \& L. I. Gordon, 1992. Oxygen solubility in seawater - better fitting equations. Limnology and Oceanography 37(6): 1307-1312.

Garland Jr., T. \& M. R. Rose, 2009. Experimental Evolution. Concepts, Methods, and Applications of Selection Experiments. University of California Press, Berkeley, Los Angeles.

Gómez, A. \& G. R. Carvalho, 2000. Sex, parthenogenesis and genetic structure of rotifers: microsatellite analysis of contemporary and resting egg bank populations. Molecular Ecology 9(2): 203-214.

Gómez, A., M. Temprano \& M. Serra, 1995. Ecological genetics of a cyclical parthenogen in temporary habitats. Journal of Evolutionary Biology 8(5): 601-622.

Guillard, R. R. \& J. H. Ryther, 1962. Studies of marine planktonic diatoms. 1. Cyclotella nana Hustedt, and Detonula confervacea (Cleve) Gran. Canadian Journal of Microbiology 8(2): 229-239. 
Haafke, J., M. Abou Chakra \& L. Becks, 2016. Eco-evolutionary feedback promotes Red Queen dynamics and selects for sex in predator populations. Evolution 70(3): 641-652.

Hessen, D. O., M. Daufresne \& H. P. Leinaas, 2013. Temperature-size relations from the cellular-genomic perspective. Biological Reviews 88(2): 476-489.

Hoefnagel, K. N. \& W. Verberk, 2015. Is the temperature-size rule mediated by oxygen in aquatic ectotherms? Journal of Thermal Biology 54: 56-65.

Horne, C. R., A. G. Hirst \& D. Atkinson, 2015. Temperaturesize responses match latitudinal-size clines in arthropods, revealing critical differences between aquatic and terrestrial species. Ecology Letters 18: 327-335.

Klok, C. J. \& J. F. Harrison, 2013. the temperature size rule in arthropods: independent of macro-environmental variables but size dependent. Integrative and Comparative Biology 53(4): 557-570.

Kozłowski, J., 1992. Optimal allocation of resources to growth and reproduction: implication for age and size at maturity. Trends in Ecology \& Evolution 7: 15-19.

Kozłowski, J., 2006. Why life histories are diverse. Polish Journal of Ecology 54(4): 585-605.

Levins, R., 1968. Evolution in Changing Environments. Some Theoretical Explorations. Princeton University Press, Princeton.

Lynch, M. \& H. W. Deng, 1994. Genetic slippage in response to sex. American Naturalist 144(2): 242-261.

Matos, M., P. Simoes, A. Duarte, C. Rego, T. Avelar \& M. R. Rose, 2004. Convergence to a novel environment: comparative method versus experimental evolution. Evolution 58(7): 1503-1510.

McNab, B. K., 2010. Geographic and temporal correlations of mammalian size reconsidered: a resource rule. Oecologia 164(1): 13-23. doi:10.1007/s00442-010-1621-5

Merilae, J. \& A. P. Hendry, 2014. Climate change, adaptation, and phenotypic plasticity: the problem and the evidence. Evolutionary Applications 7(1): 1-14.

Mills, S., J. A. Alcantara-Rodriguez, J. Ciros-Perez, A. Gomez, A. Hagiwara, K. I. Galindo, C. D. Jersabek, R. Malekzadeh-Viayeh, F. Leasi, J. S. Lee, D. B. M. Welch, S. Papakostas, S. Riss, H. Segers, M. Serra, R. Shiel, R. Smolak, T. W. Snell, C. P. Stelzer, C. Q. Tang, R. L. Wallace, D. Fontaneto \& E. J. Walsh, 2017. Fifteen species in one: deciphering the Brachionus plicatilis species complex (Rotifera, Monogononta) through DNA taxonomy. Hydrobiologia. doi:10.1007/s10750-0162725-7.

Miracle, M. R. \& M. Serra, 1989. Salinity and temperature influence in rotifer life-history characteristics. Hydrobiologia 186: 81-102.

Montero-Pau, J., E. Ramos-Rodriguez, M. Serra \& A. Gómez, 2011. Long-term coexistence of rotifer cryptic species. PLoS ONE. doi:10.1371/journal.pone.0021530.

Nisbet, E. G. \& C. M. R. Fowler, 1996. Early life - Some liked it hot. Nature 382(6590): 404-405.

Ortells, R., A. Gómez \& M. Serra, 2003. Coexistence of cryptic rotifer species: ecological and genetic characterisation of Brachionus plicatilis. Freshwater Biology 48(12): 2194-2202. doi:10.1046/j.1365-2427.2003.01159.x

Pace, N. R., 1991. Origin of life - facing up to the physical setting. Cell 65(4): 531-533.
Pintor, A. F. V., L. Schwarzkopf \& A. K. Krockenberger, 2015. Rapoport's Rule: do climatic variability gradients shape range extent? Ecological Monographs 85(4): 643-659.

Roff, D. A., 1992. The Evolution of Life Histories: Theory and Analysis. Chapman \& Hall, New York.

Ruttner-Kolisko, A., 1977. Suggestions for biomass calculation of plankton rotifers. Archiv für Hydrobiohgie Beiheft 8: 71-76.

Sanjuan, R. \& P. Domingo-Calap, 2011. Experimental evolution in viruses. Wiley, Chichester.

Smith, H. A. \& T. W. Snell, 2014. Differential evolution of lifespan and fecundity between asexual and sexual females in a benign environment. International Review of Hydrobiology 99(1-2): 117-124.

Stearns, S. C., 1992. The Evolution of Life Histories. Oxford University Press, Oxford.

Stelzer, C. P., 2011. The cost of sex and competition between cyclical and obligate parthenogenetic rotifers. American Naturalist 177(2): E43-E53.

Stelzer, C. P. \& T. W. Snell, 2006. Specificity of the crowding response in the Brachionus plicatilis species complex. Limnology and Oceanography 51(1): 125-130.

Swallow, J. G. \& T. Garland, 2005. Selection experiments as a tool in evolutionary and comparative physiology: Insights into complex traits - An introduction to the symposium. Integrative and Comparative Biology 45(3): 387-390.

Takemoto, K. \& T. Akutsu, 2008. Origin of structural difference in metabolic networks with respect to temperature. Bmc Systems Biology. doi:10.1186/1752-0509-2-82.

Tarazona, E., E. M. Garcia-Roger \& M. J. Carmona, 2017. Experimental evolution of bet hedging in rotifer diapause traits as a response to environmental unpredictability. Oikos in press. doi:10.1111/oik.04186.

Taylor, M. L., A. Skeats, A. J. Wilson, T. A. R. Price \& N. Wedell, 2015. Opposite environmental and genetic influences on body size in North American Drosophila pseudoobscura. Bmc Evolutionary Biology. doi:10.1186/ s12862-015-0323-3.

Teplitsky, C. \& V. Millien, 2014. Climate warming and Bergmann's rule through time: is there any evidence? Evolutionary Applications 7(1): 156-168.

Verberk, W. C. E. P., D. T. Bilton, P. Calosi \& J. I. Spicer, 2011. Oxygen supply in aquatic ectotherms: partial pressure and solubility together explain biodiversity and size patterns. Ecology 92(8): 1565-1572.

Walczyńska, A. \& M. Serra, 2014a. Inter- and intraspecific relationships between performance and temperature in a cryptic species complex of the rotifer Brachionus plicatilis. Hydrobiologia 734: 17-26.

Walczyńska, A. \& M. Serra, 2014b. Species size affects hatching response to different temperature regimes in a rotifer cryptic species complex. Evolutionary Ecology 28: 131-140.

Walczyńska, A., A. M. Labecka, M. Sobczyk, M. Czarnoleski \& J. Kozłowski, 2015. The temperature-size rule in Lecane inermis (Rotifera) is adaptive and driven by nuclei size adjustment to temperature. Journal of Thermal Biology 54: 78-85.

Wetzel, R. G., 2001. Limnology. Lake and river ecosystems. Elsevier Academic Press, San Diego, San Francisco, New York, Boston, London, Sydney, Tokyo. 
Whitman, D. W. \& A. A. Agrawal, 2009. What is phenotypic plasticity and why is it important? In Whitman, D. W. \& T. N. Ananthakrishnan (eds), Phenotypic Plasticity of Insects: Mechanisms and Consequences. Science Publishers, Enfield: 1-63.
Woese, C. R., 1987. Bacterial evolution. Microbiological Reviews 51(2): 221-271.

Woods, H. A., 1999. Egg-mass size cell size: effects of temperature on oxygen distribution. American Zoologist 39: 244-252. 